\title{
A study on the Barriers in Accessibility for the Disabled at Bus Terminal
}

\author{
Lee Yin Mun ${ }^{1}$, Wai Kun $X^{1}{ }^{1}$, and Salini Devi Rajendran ${ }^{1 *}$ \\ ${ }^{1}$ Faculty of Business and Information Science, UCSI University, Jalan Menara Gading, 56000 Cheras, Kuala Lumpur, Malaysia
}

\begin{abstract}
Transportation is a highly significant issue for the people with disabilities. The lack of accessibility in bus terminal has led to drawbacks and restricts many of the disabled from moving around without any restriction. The purpose of this research is to identify the barriers of accessibility for the disabled in bus terminals in Malaysia. The main objective of this work was to analyze the level of satisfaction of disabled toward the accessibility in bus terminal and identify the barriers of accessibility for disabled in bus terminal. This study is only focusing on the structural barriers. There are five factors affecting the structural barriers which are infrastructure, pedestrian environment, vehicle design, planning and information. The relationship between these variables and accessibility of disabled people in bus terminal was studied. This work was carried out based on quantitative research method. Questionnaire was used for data collection and data analysis was done using SPSS software in terms of inferential analysis. The key findings of this work showed that all variable has a significant relationship with accessibility of disabled people in bus terminal.
\end{abstract}

\section{INTRODUCTION}

Accessibility can be defined as the ability to access the functionality and possible benefit of some structure and is used to express the extent to which a product such as a facility, service, environment is accessible by people [1]. Transportation is a highly significant issue for the people with disabilities [2]. The lack of accessibility in bus terminal has led to drawbacks and restricts many of the disabled from moving around without any restriction [2].

Even though through existence of technology advanced facilities, not all of the people are able to make use of it due to limited accessibility for the disabled people such as wheelchair users, vision impairment, and hearing impairment [3]. Fredman [4] reported that disabled people does not have equal treatment compared to normal people, and also highlighted that the disabled people are unique and they have a disadvantage in accessibility in use of the facilities in the urban area that requires immediate attention.

According to Zhou [5], in order to facilitate the accessibility to public transportation for the disabled people, different advancements shall take place especially to vehicles (buses, trains, etc), infrastructure and information.

Good traveler information such as knowing the stop at destination, knowing the platform for departure, how to access information especially for the disabled is an important part of the public transport service. It leads to the contribution to the overall quality service and convenience of the public transport service [6].

Generally, most people with disability (PWD) face faced significant barriers to mobility such as structural barriers, social barrier and psychological barriers [7]. In terms of transportation, structural barrier is an important factor that influences the mobility of people with disability (PWD) [8]. Insufficiency and improper design of infrastructure presents is structural barrier to the PWDs [9]. Many transport terminals still lack in terms of facilities or infrastructures which lead to a serious issue and it is a need to ensure the convenience for everyone [8, 9]. Regardless to the transportation modes, some facts are true of disabled travelers. Compared with non-disabled, person with disabilities (PWD) can be more vulnerable to accidents [10].

The pedestrian environment can be the first barrier to PWD when they are making a trip [11]. Small et al. [12] stated that the insufficiency of paved road and uneven surfaces are the common problem faced by the PWD. It increases the vulnerability of PWD to injuries. In addition the hazards left open without proper warning or notice, and improper parking of vehicles affect the pedestrian safety as well as their accessibility [12].

The safety of the surrounding environment also shall be assessed such potholes on the pedestrian area. These are the issues which lead to the inaccessibility of the infrastructure especially for the wheelchair users and vision impairment people [12]. Normal people will avoid walking on the uneven pavements or potholes due to feeling unsafe while walking on the pavement but it will be difficult especially for the wheelchair users and vision impaired people to avoid it as they are not able to avoid or to see the uneven pavement or potholes [13].

The bus design and structure often present a major barrier to PWD. The common barriers faced by PWD due the improper vehicle design are high entry steps, insufficient of handrails at the entrance and inside of the

*Corresponding author's e-mail: salinidevi@ucsiuniversity.edu.my 
bus, narrow doors, no space for wheelchair users, slippery and uneven vehicle floors [14]. Disabled passengers with serious walking difficulties, calipers users as well as wheelchair users were not able to get up and down from the bus independently [14].

Stock et al. [15] reported that, the PWD should be given equal opportunities to travel as a citizen and it is important that the services that they depend on are reachable and available for them.

In order to have a good planning on the journey of the PWD, good information must be available [6]. Different group of travelers need different volume and different kind of information as different group of travelers may look for different types of information [6]. The younger generations may look for convenience in bus transfers among different terminals while disabled people may want to know if there is handicap lavatory on board. Another issue is that the traveler information that specifies the needs of the PWD is unreliable even when available [6]. The information should be available for disabled people all the time in order for them to travel independently using bus service. The staffs at the bus terminal play an important role in assisting the disabled people in order to provide them with the correct information. However, transport staff can also create barriers for the PWDs using the public transport. The PWDs often reported that assistance provided by the staff were not enough and sufficient [16].

Malaysia is moving toward to become a developed country. The government has been improving the public transportation system to provide the passengers with a more convenient and comfortable experience in taking public transport [17]. This is to encourage individuals to take public transport more frequently.

Even though there are advancement and improvement in the public transportation system, most of the public transport terminals are still lacking of good and proper facilities and design to ensure convenience to all groups of passengers, especially person with disabilities. Those disabled face a lot of challenges and barriers when they are travelling using public transport because of the poor accessibility of public transport terminal [17]. Although the government has set up some facilities for the disabled, there are still deficiencies in those facilities. The accessibility of transportation for disabled in not of the priority. In addition, Soltani [18] reported that Malaysia is lacking in considering providing equal and same accessibility as well as facilities to the disabled. As a result, the inaccessibility of the transportation facilities will lead to inconvenience for the disabled and it may affect the choice to travel by public transport due to insecurity and uncertainty of being able to move and travel around freely.

This paper aims to study about the problem of accessibility for disabled in bus terminal. The purpose of this research is to identify the barriers of accessibility for the disabled in bus terminals in Malaysia where the level of satisfaction of disabled toward the accessibility in bus terminal was analyzed and the barriers of accessibility was evaluated.

\section{METHODOLOGY}

\subsection{Research Design}

This work is based on explanatory study. This work was done to analyzed relationship between the barriers in accessibility and the five factors. The five factors selected are infrastructure, pedestrian environment, information, vehicle design and planning. These factors were used in our study as independent variables (IVs) with the relationship of accessibility of disabled people in bus terminal, dependent variable (DV) as shown in Figure 1. Quantitative research method will be carried out to justify the dependent and independent variables of the barriers in accessibility for the disabled.

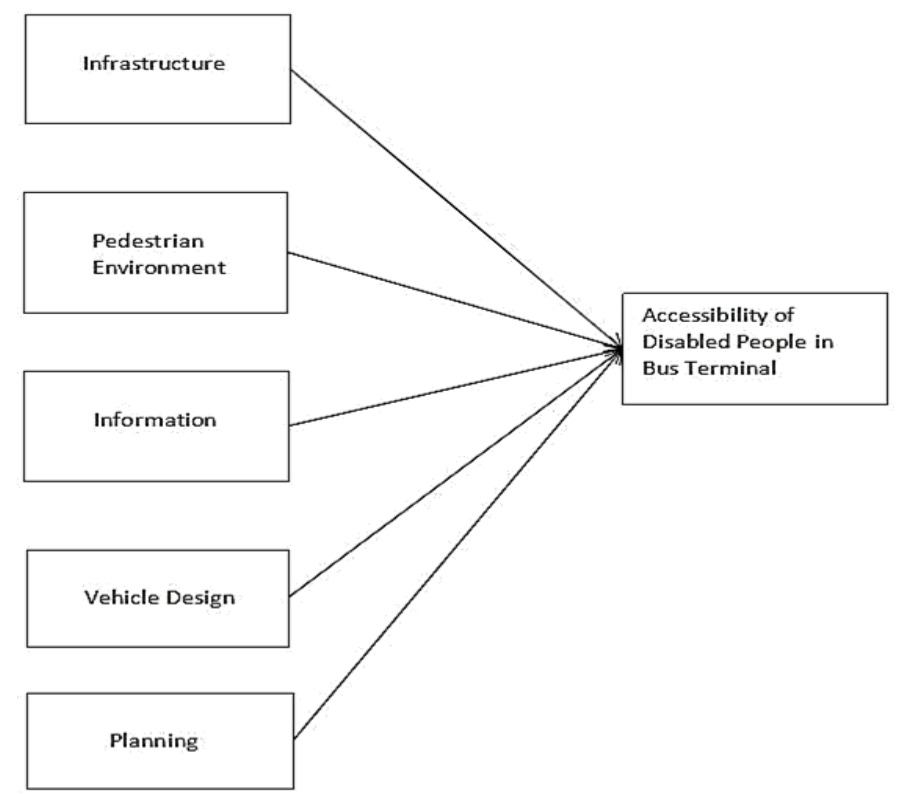

Figure 1. Research Framework 


\subsection{Hypothesis}

For this work, several hypotheses were deduced. The hypothesis under study is stated as follow. H01: There is no significant relationship between infrastructures towards accessibility of disabled in bus terminal. H11: There is a significant relationship between infrastructures towards accessibility of disabled in bus terminal. H02: There is no significant relationship between pedestrian environments towards accessibility of disabled in bus terminal. H12: There is a significant relationship between pedestrian environments towards accessibility of disabled in bus terminal. H03: There is no significant relationship between vehicle designs towards accessibility of disabled in bus terminal. H13: There is a significant relationship between vehicle designs towards accessibility of disabled in bus terminal. H04: There is no significant relationship between planning towards accessibility of disabled in bus terminal. H14: There is a significant relationship between planning towards accessibility of disabled in bus terminal. H05: There is no significant relationship between information towards accessibility of disabled in bus terminal. H15: There is a significant relationship between information towards accessibility of disabled in bus terminal.

\subsection{Data Collection}

In this research, quantitative method is used as it can examine the relationship between dependent and independent variables. Questionnaire will be used to collect all the relevant information from the target respondent. In this research, quantitative approach is being used because we tend to examine the relationship between barriers in accessibility and the five factors at the bus terminal. Primary data was collected from the questionnaire. In this research, most of the secondary data collected and used are related to the accessibility barriers for the disabled people at bus terminals.
The target population for this study will be the disabled people such as people with disability, wheelchair users, people with visual impairment and hearing impairment regardless of nationalities at bus terminals in Klang Valley. In addition, the respondents in this study must be the one who access the bus terminal and uses the infrastructure and facilities. The sampling location of this study will be focusing at Klang Valley [19]. Questionnaires prepared will only be distributed and tested on the disabled people who go through their journey by the public transportation which is bus, which also means that the people who access to the facilities and infrastructures at the bus terminal. The sample size for this work is 103 respondents. In this research, convenience sampling, which is a non-probability sampling method, is used.

\subsection{Data Analysis}

Data gathered was analyzed by using statistics software SPSS and inferential method to evaluate the hypothesis of this work. In addition, validity and reliability test was done for this quantitative data as it is important to see if the data is accurate $[20,21]$ by getting proportion of systematic variation in a scale [22] by using Cronbach's Alpha to measure the internal consistency [23].

\section{RESULT AND DISCUSSION}

\subsection{Normality Test}

Table 1 shows the outcome for the normality test. In this normality test, based on Table 1, skewness values as well as the kurtosis values are acceptable between -1 and +1 . The skewness as well as the kurtosis of dependent variable (DV) is 0.260 and -0.423 . For the skewness and kurtosis of infrastructure, the value is 0.148 and -0.182 , pedestrian environment is 0.027 and -0.655 , vehicle design is 0.102 and -0.451 , planning is 0.384 and -0.465 and, lastly, information is -0.025 and -0.294 .

\subsection{Sampling and Population}

Table 1. Final Test of Normality Test for Dependent Variable and Independent Variables

\begin{tabular}{ccccc}
\hline Variable & \multicolumn{2}{c}{ Skewness } & \multicolumn{2}{c}{ Kurtosis } \\
\cline { 2 - 5 } & Statistic & Std Error & Statistic & Std Error \\
\hline Accessibility of Disable & 0.260 & 0.238 & -0.423 & 0.472 \\
in Bus -DV & & & & 0.472 \\
Infrastructure -IV & 0.148 & 0.238 & -0.182 & 0.472 \\
Pedestrian -IV & 0.027 & 0.238 & -0.655 & 0.472 \\
Vehicle Design & 0.102 & 0.238 & -0.451 & 0.472 \\
Planning & 0.384 & 0.238 & -0.465 & 0.472 \\
Information & -0.025 & 0.238 & -0.294 & \\
\hline
\end{tabular}

\subsection{Reliability Test}

Cronbach's alpha is one of the theories used to test the reliability of the variables, the higher the coefficient, the more the items are reliable and probably measure the same underlying concepts. Value of Cronbach's alpha that is exceeding 0.8 will be defined as it is an excellent reliability. Poor reliability is defined as when the value is 0.6 and below. Value of Cronbach's alpha that is 0.7 and higher is considered as an acceptable reliability. Based on Table 2, according to Cronbach's Alpha, the reliability of every variable was within acceptable range if the value is 0.7 and above. Dependent variable has a value of 0.732 . Besides, for the independent variable, infrastructure has a value of 0.693 , pedestrian 
environment is 0.712 , vehicle design is 0.754 , planning is 0.678 and information is 0.688 . Lastly, the average of
Cronbach's alpha value is 0.710 , which falls in the acceptable range.

Table 2. Final Test of Reliability Test for Dependent Variable

\begin{tabular}{cc}
\hline Factor & Crocbach's Alpha \\
\hline DV- Accessibility of disabled in bus terminal & 0.732 \\
IV- Infrastructure & 0.693 \\
IV- Vehicle Design & 0.712 \\
IV- Pedestrian Environment & 0.754 \\
IV- Planning & 0.678 \\
IV- Information & 0.688 \\
\hline
\end{tabular}

\subsection{Pearson Correlation Coefficient Test}

The purpose of using Pearson correlation coefficient test is to explore the strength of linear relationship between two continuous variables. Table 3 shows the summary of Pearson correlation test. Based on Table 3, the first independent variable (IV), infrastructure, has a moderate positive moderate relationship $(\mathrm{r}=0.308,0.3<\mathrm{r} 0.5)$ with accessibility in bus terminal. Secondly for pedestrian environment, it has positive and strong relationship with strong strength of association $(r=0.700, r>0.5)$ with accessibility in bus terminal. Thirdly, there is positive and strong strength of association $(\mathrm{r}=0.815, \mathrm{r}>0.5)$ relationship with accessibility in bus terminal. For the fourth IV, planning, it has a moderate and positive strength of association $(r=0.369,0.30<r<0.5)$ relationship with accessibility in bus terminal. For the fifth IV, information, it has a positive and strong strength of association $\quad(\mathrm{r}=0.594, \quad \mathrm{r}>0.5) \quad$ relationship with accessibility in bus terminal.

Table 3. Summary Results of Correlation

\begin{tabular}{cc}
\hline Variables & Pearson correlation \\
\hline IV- Infrastructure & 0.308 \\
IV- Pedestrian Environment & 0.700 \\
IV- Vehicle Design & 0.815 \\
IV- Planning & 0.369 \\
IV- Information & 0.594 \\
\hline
\end{tabular}

\subsection{Multiple Regression Analysis}

Table 4 shows the model summary. Based on Table 4 , it shows the model summary of multiple linear regressions. It generates the value of $\mathrm{R}$ and $\mathrm{R}$ Square in order to find the adjusted $\mathrm{R}$ Square of the model. Furthermore, the $\mathrm{R}$ value is 0.852 which is near to 1 and it means the relationship between accessibility of disabled in bus terminal (DV) and infrastructure, pedestrian environment, vehicle design, planning, information is strong. For $\mathrm{R}$ Square, it has a value of 0.726 , which represent $72.6 \%$ of five variables, infrastructure, pedestrian environment, vehicle design, planning and information contribute to accessibility of disabled in bus terminal (DV). The remaining percentage which is $27.4 \%$ of change cannot be estimated

Table 4. Model summary

\begin{tabular}{ccccc}
\hline Model & R & R Square & Adjusted R Square & Std. Error of the Estimate \\
\hline 1 & $.852^{\text {a }}$ & .726 & .711 & 1.43844 \\
\hline
\end{tabular}

a. Predictors: (Constant), IV1, IV2, IV3, IV4, IV5.

b. Dependent Variable: DV

Table 5 shows coefficients of regression analysis. Based on Table 5, if the value of $t$ is positive, the independent variable has positive relationship with the dependent variable. In contrast, negative value represents a negative relationship between independent variable and dependent variable. From the table above, it clearly shows that $t$ value of vehicle design (IV 3) is 6.261 which mean it has the strongest positive relationship with accessibility of disabled in bus terminal. On the other hand, $t$ value of infrastructure (IV 1) is 2.036 which have the weakest positive relationship compared with all other independent variables

Table 5. Coefficients of Regression Analysis

\begin{tabular}{|c|c|c|c|c|c|}
\hline \multirow[t]{2}{*}{ Model } & \multicolumn{2}{|c|}{ Unstandardized Coefficients } & \multirow{2}{*}{$\begin{array}{c}\text { Standardized } \\
\text { Coefficients }\end{array}$} & \multirow[t]{2}{*}{$\mathbf{t}$} & \multirow[t]{2}{*}{ Sig. } \\
\hline & B & Std Error & & & \\
\hline 1Constant & -.678 & .053 & & -.407 & .685 \\
\hline IV1 & .124 & .100 & .120 & 2.036 & .044 \\
\hline IV2 & .229 & .031 & .258 & 3.407 & .001 \\
\hline IV3 & .446 & .058 & .521 & 6.261 & .000 \\
\hline IV4 & .141 & .102 & .138 & 2.359 & .020 \\
\hline IV5 & .135 & .018 & .157 & 2.396 & .018 \\
\hline
\end{tabular}

Thus, based on Table 5, the following model of multiple linear regressions was attained. $y=\alpha+\beta 1$
$($ Infrastructure $)+\beta 2$ (Pedestrian Environment) $+\beta 3$ $($ Vehicle Design $)+\beta 4$ (Planning) $+\beta 5$ (Information $)+\varepsilon$, 
thus $\mathrm{y}=-0.678+0.124$ (Infrastructure) +0.229 (Pedestrian Environment) +0.446 (Vehicle Design) + 0.141 (Planning) +0.135 (Information).

From the equation, $y$ represents dependent variable, $\mathrm{x}$ represents independent variable and $\varepsilon$ represents the error. Besides, the B-value for infrastructure is 0.124, pedestrian environment is 0.229 , vehicle design is 0.446 , planning is 0.141 and information is 0.135 . The results are all positive. For regression constant, it has a value of -0.678. According to this model, prediction explains the total value of dependent variable change as the value of independent variable increases or decreases. Moreover, this equation explains that if infrastructure factor rises by 1 unit, the accessibility of disabled people in bus terminal will increase by 0.124 unit. When pedestrian environment factor increases by 1 unit, the accessibility of disabled people in bus terminal will increase by 0.229 . When vehicle design factor increases by 1 unit, the accessibility of disabled people in bus terminal will increase by 0.446 unit. Besides, when the planning factor increases by 1 unit, the accessibility of disabled people in bus terminal will increase by 0.141 unit. Lastly, when the information factor increases by 1 unit, the accessibility of disabled people in bus terminal will increase by 0.135 unit

The p-value of infrastructure is 0.044 , pedestrian environment is 0.001 , vehicle design is 0.000 , planning is 0.020 and information is 0.018 . All the p-value results are lower than 0.05 and it means all the independent variables would affect the dependent variable in the research

\subsection{Overall Discussion}

Based on the result of multiple linear regression and pearson correlation coefficient test, the outcome of the hypothesis will be discussed. There are five hypotheses that were tested and their relationship with dependent variable is discussed.

The correlation for infrastructure factor is 0.308 , which is between 0.3 and 0.5 , so it has a positive relationship with a moderate strength of association. Besides, the p-value of infrastructure is 0.044 , which is lower than 0.05 , so it may affect accessibility of disabled in bus terminal. Therefore, we rejected H01 and accepted H11.

Secondly, the value of correlation of pedestrian environment is 0.700 , which has a positive relationship with strong strength of association with accessibility of disabled in bus terminal. Besides, p-value of pedestrian environment is 0.001 which is lower than 0.05 . Therefore, we rejected $\mathrm{H} 02$ and accepted $\mathrm{H} 12$.

Thirdly, the value of correlation of vehicle design is 0.815 , therefore it has positive relationship with strong strength of association. Besides, the p-value of vehicle design is 0.000 , which is lower than 0.05 . Therefore, we rejected $\mathrm{H} 03$ and accepted $\mathrm{H} 13$.

Fourthly, the value of correlation of planning is 0.369 , therefore it has positive relationship with moderate strength of association. Besides, p-value of planning is
0.020 , which is lower than 0.05 . Therefore, we rejected H04 and accepted H14.

Finally, the value of correlation of information is 0.594 , which is more than 0.5 , therefore, it has positive relationship with strong strength of association with accessibility of disabled in bus terminal. Besides, the pvalue of information is 0.018 , which is lower than 0.05 . Therefore, we rejected $\mathrm{H} 05$ and accepted H15.

\section{CONCLUSION}

The objectives of this research are to find out the factors that are affecting the accessibility of disabled people in bus terminal and the satisfaction of disabled people towards accessibility in bus terminal. In this study, questionnaires have been generated to facilitate a survey on barriers in accessibility for the disabled and better understanding of facilities at the bus terminal. The outcome of this work showed that all the independent variable had significant relationship with accessibility of disabled in bus terminal. There are total of five factors affecting the accessibility of disabled in bus terminal, which are infrastructure, pedestrian environment, vehicle design, planning and information. The accessibility problem in bus terminal leads to inconveniency of PWDs to use bus transportation. Besides, due to improper and ineffective facilities, vehicle designs and planning of authorities and policy makers of bus terminal, it affects the accessibility of disabled in bus terminal and it causes them to use other mode of transportation. Lastly, the authorities and policy makers need to be concerned of the needs of disabled and non-disabled in taking bus transportation. It is important to treat everyone in the society equally and disabled people should have equal treatment compared to non-disabled. In this study, the data we gained is not great and accurate as there are only a total of 103 respondents. We suggest that researchers in the future to use greater scale in order to acquire reliable data.

\section{References}

1. Hill, H. (2013). Disability and accessibility in the library and information science literature: A content analysis. Library \& Information Science Research, 35(2), 137-142.

2. Lubin, A., \& Deka, D. (2012). Role of public transportation as job access mode: Lessons from survey of people with disabilities in New Jersey. Transportation Research Record: Journal of the Transportation Research Board, (2277), 90-97.

3. Lee, B. K., Agarwal, S., \& Kim, H. J. (2012). Influences of travel constraints on the people with disabilities' intention to travel: An application of Seligman's helplessness theory. Tourism Management, 33(3), 569-579.

4. Fredman, S. (2017). Disability equality: A challenge to the existing anti-discrimination paradigm?. In Disability and Equality Law (pp. 123-142). Routledge. 
5. Zhou, H., Hou, K. M., Zuo, D., \& Li, J. (2012). Intelligent urban public transportation for accessibility dedicated to people with disabilities. Sensors, 12(8), 10678-10692.

6. Buhalis, D., Darcy, S., \& Ambrose, I. (Eds.). (2012). Best practice in accessible tourism: Inclusion, disability, ageing population and tourism. Channel View Publications.

7. Nhamo, E., \& Sibanda, P. (2014). Reviewing benefits and barriers associated with the participation of persons with disabilities in sport, exercise, physical and leisure activities. International journal of science and research, 3(8), 304-307.

8. Lubin, A., \& Deka, D. (2012). Role of public transportation as job access mode: Lessons from survey of people with disabilities in New Jersey. Transportation Research Record: Journal of the Transportation Research Board, (2277), 90-97.

9. Kerbler, B. (2012). A toolkit for detecting and eliminating the barriers that people with disabilities face in the built environment: the case of Slovenia, Europe/Engellilerin yapili cevrede karsilastiklari engelleri saptamak ve gidermek icin bir arac seti: Slovenya ornegi, Avrupa. METU Journal of the Faculty of Architecture, 29(2), 235-258.

10. Hästbacka, E., Nygård, M., \& Nyqvist, F. (2016). Barriers and facilitators to societal participation of people with disabilities: A scoping review of studies concerning European countries. Alter, 10(3), 201220.

11. Jamaludin, M., \& Kadir, S. A. (2012). Accessibility in buildings of tourist attraction: A case studies comparison. Procedia-Social and Behavioral Sciences, 35, 97-104.

12. Marisamynathan, \& Perumal, V. (2014). Study on pedestrian crossing behavior at signalized intersections. In CICTP 2014: Safe, Smart, and Sustainable Multimodal Transportation Systems (pp. 2641-2652).

13. Small, J., Darcy, S., \& Packer, T. (2012). The embodied tourist experiences of people with vision impairment: Management implications beyond the visual gaze. Tourism Management, 33(4), 941-950.

14. Carmien, S., Dawe, M., Fischer, G., Gorman, A.,
Kintsch, A., \& Sullivan Jr, J. F. (2005). Sociotechnical environments supporting people with cognitive disabilities using public transportation. ACM Transactions on ComputerHuman Interaction (TOCHI), 12(2), 233-262.

15. Stock, S. E., Davies, D. K., Wehmeyer, M. L., \& Lachapelle, Y. (2011). Emerging new practices in technology to support independent community access for people with intellectual and cognitive disabilities. NeuroRehabilitation, 28(3), 261-269.

16. Shapiro, J. P. (2011). No pity: People with disabilities forging a new civil rights movement. Broadway Books.

17. Kamarudin, H., Hashim, A. E., Mahmood, M., Ariff, N. R. M., \& Ismail, W. Z. W. (2012). The implementation of the Malaysian Standard Code of Practice on access for disabled persons by local authority. Procedia-Social and Behavioral Sciences, 50, 442-451.

18. Soltani, S. H. K., Sham, M., Awang, M., \& Yaman, R. (2012). Accessibility for disabled in public transportation terminal. Procedia-Social and Behavioral Sciences, 35, 89-96.

19. Wahab, S.N., Lay, Y.F., Koay, W.L., \& Hussin, A.A.A, (2019). Usage of Pedestrian Bridge among the Urban Commuters in Kuala Lumpur. International Journal of Operational Research, DOI: 10.1504/IJOR.2021.10019276.

20. Sham, R., Wahab, S.N., Anuar, M.M., Tong, W.H. \& Yap, J.T. (2019). Safety Indicator for Taxi Users in Urban Area. International Journal of Supply Chain Management, 8(2), pp. 1035-1041.

21. Wong, C. H., Tan, G. W. H., Tan, B. I., \& Ooi, K. B (2015). Mobile advertising: the changing landscape of the advertising industry. Telematics and Informatics, 32(4), 720-734.

22. Wahab, S.N., \& Khong W.L. (2018). Multiple Linear Regression Modelling of Parcels' Distribution Design Factors and online Shopping Customer Satisfaction. International Journal of Modelling in Operations Management, 7(2), 95-110.

23. Rajendran, S.D., Wahab, S.N, Ling, Y.W., and Yun, L.S. (2018) The Impact of Logistics Services On the E-Shoppers' Satisfaction, International Journal of Supply Chain Management, 7(5), 461-469. 